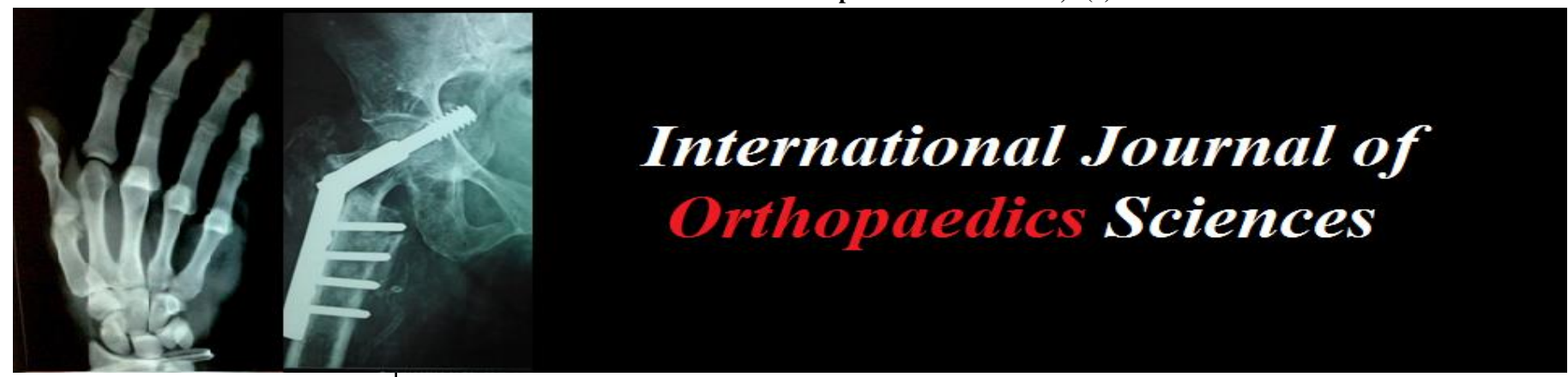

ISSN: $2395-1958$

IJOS 2018; 4(3): 398-407

(C) 2018 IJOS

www.orthopaper.com

Received: 11-05-2018

Accepted: 12-06-2018

Dr. Kumar Anshuman

Associate Professor, Department of Orthopedics, Narayan Medica College, Sasaram, Bihar, India

Gourishankar Patnaik Professor and Head, Department of Orthopedics, Narayan Medical College, Sasaram, Bihar, India

Correspondence

Dr. Kumar Anshuman

Associate Professor, Department of Orthopedics, Narayan Medical College, Sasaram, Bihar, India

\section{A comparative study of closed reduction and fixation with percutaneous $k$-wires versus open reduction and internal fixation with philos plate for proximal humerus fractures in the elderly}

\section{Dr. Kumar Anshuman and Gourishankar Patnaik}

DOI: https://doi.org/10.22271/ortho.2018.v4.i3h.71

Abstract

The aim of this study is to compare and evaluate functional, clinical and radiological outcome achieved by open reduction and internal fixation by Philos plate \& percutaneous k-wire fixation of proximal humerus fracture in the elderly patients.

In conclusion, locking Compression plate has a distinct advantage in treatment of proximal humeral fractures. This is due to angular stability, compression of fragment particularly in comminuted fractures and in Osteoporotic bones in elderly patients, thus allowing early mobilization. Percutaneous k-wire fixation can be a viable option in elderly patients where several comorbidities. They are particularly useful where we are dealing with patients who have constraint of finances and anesthestic risks of long hours of surgery.

Keywords: Philos plate, percutaneous k-wire fixation, proximal humerus fracture

\section{Introduction}

Proximal humerus fractures are one of the commonest fractures occurring in the skeleton. They account for approximately $4-5 \%$ of the all fracture ${ }^{[2,3]}$. The incidence of fracture is more common in elderly because of osteoporosis and decreased bone density. However, it can occur in younger age group following high velocity trauma ${ }^{[3]}$.

The management of proximal humeral fractures can be challenging because of various destabilizing factors at the fracture site. Numerous muscles attachment and paucity of space for fixing implant and osteoporosis complicate the fractures of proximal humerus. The treatment is further challenging if we are dealing with intra articular fractures as they carry a high risk of the humeral head necrosis. In Neer's classification, these are two part anatomical neck, three-part and four-part fracture and those with dislocation of head of humerus. A review of published result suggests that there is no universally accepted form of treatment. Conservative management may be associated with nonunion, malunion, and avascular necrosis resulting in painful dysfunction ${ }^{[4,5,6]}$.

Operative option is considered after the patient's general condition permits for safer anesthesia. A delay of several days makes reduction more difficult and a significant delay results in absorption of bone, making secure internal fixation impossible ${ }^{[6]}$.

The object of the osteosynthesis is to reduce the displacement of each fragment and hold it in place with an implant. Thus, the greater tuberosity fragment, which usually displaces proximally and is rotated upward by the attached rotator cuff muscles, is fixed to the major humeral head fragment. Similarly the lesser tuberosity fragment displaced by subscapularis is fixed to the humeral head fragment

Three \& four part fractures represent 13 to $16 \%$ of proximal humeral fractures. Treatment options for these displaced fractures include open reduction and fixation. Neer recommended open reduction and internal fixation for displaced two and three parts fractures ${ }^{[3]}$.

Most of the poor results following open reduction and internal fixation of three-part fracture are due to imperfect technique. 
In a three or four part fracture or fracture dislocation, when the head of the humerus is entirely devoid of any blood supply it can be replaced by a humeral prosthesis.

However, the goal of proximal humerus fracture fixation should be stable reduction allowing early mobilization. The present study analyzes fractures of the proximal humerus that were treated with percutaneous k-wires versus philos and documents their clinical and functional outcome. With this background, we have chosen "A comparative study of closed reduction and fixation with percutaneous k-wires versus open reduction and internal fixation with philos plate for proximal humerus fractures in the elderly" as my research topic to evaluate the results.

\section{Materials and methods}

Source of the data: All patients fulfilling the inclusion criteria were admitted Narayan Medical College \& Hospital, Jamuhar, Sasaram during the study period from May 2017 to April 2018

\section{Method of collection of data}

The study includes patients with proximal humerus fractures admitted and examined according to protocol. The associated injuries were documented. Clinical and radiological evaluation done. Fractures were classified using Neer's classification. Routine hematological investigation carried out to get as per the anesthetist requirement for surgery. An informed consent was obtained from the patient and his/her relatives. Patients were randomly selected for closed reduction and percutaneous $\mathrm{k}$-wire fixation under $\mathrm{C}$-arm control and Open reduction internal fixation with PHILOS under general anaesthesia. Postoperatively patients were put on physiotherapy according to standard protocol, to evaluate the functional outcome.

A randomised prospective study of 30 cases has been studied without any sampling procedure in our institute from May 2017 to April 2018. Proper written consent was taken before surgery.

Group A: Included 15 patients were treated with ORIF with PHILOS plate.

Group B: Included 15 patients who were treated with percutaneous k-wire fixation method.

\section{Inclusion criteria}

- Two part, three part, four part proximal humeral fractures.

- $\quad$ Acute fracture

- Age above 55

- Patient fit for surgery

- Proximal humerus fracture operated within 2-7 days with or without associated injuries

\section{Exclusion criteria}

- Associated humerus shaft fracture

- Associated neurovascular injury

- Acute infection

- Pathological fractures

- $\quad$ Old fractures

- Compound fracture

\section{Study design}

A randomized controlled clinical study.

Sample size: 30
The study conducted in two groups

Group A: 15 Elderly patients treated with open reduction and internal fixation with PHILOS.

Group B: 15 Elderly patients treated with percutaneous Kwire fixation.

On admission of the patient a careful history was elicited from the patients and/or attendants of injury and the severity of trauma. As patients belonged to older age group, they were examined for co morbidity and the clinical conditions were documented and pre-anesthetic checkup was advised.

A thorough clinical examination to rule out other fractures was done. The local examination of injured shoulder was evaluated for swelling, deformity, loss of function and altered attitude. Any nerve injury was also looked for and noted. Local neurologic deficit of axillary nerve was also assessed by looking for anaesthetic patch over lateral aspect of shoulder. Radiograph of proximal humerus were taken and fractures were classified according to Neer's classification. Next the limb was immobilized in U-slab and arm-pouch.

The patient was taken for surgery after routine investigation and after obtaining medical fitness towards surgery.

- The investigations are as follows: CBC, PT/APTT/INR, urine for sugar, FBS, PPBS, Blood urea, serum creatinine, HIV, HbsAg and ECG, chest-X ray.

- An informed consent for surgery was taken from the patient and attendants after explaining the procedure and possible complications.

- Injection Tetanus toxoid and brad spectrum antibiotics were given 1 hour preoperatively.

\section{Randomization and allocation concealment}

The eligible candidates were offered treatment option in form of two identical sealed envelope. The treatment modality for the particular patient was given what he/she chose and groups were allocated accordingly.

General anesthesia was used in all patients (Both group A and B)

\section{Patient position and draping}

Patients placed in supine position on operating table with wedge a sandbag under the spine and medial border of scapula to push the affected side forward while allowing the arm to fall backward. The arm was draped free, as it will have to be moved during the approach.

\section{Surgical approaches \\ Group-A \\ Deltopectoral approach \\ Procedure ${ }^{[30,27,45]}$}

All patients received a prophylactic dose of $1.5 \mathrm{gm}$ cefuroxime $+500 \mathrm{mg}$ of amikacin intravenously preoperatively. The operation was done in supine position with small sand bag under shoulder, under general anesthesia. Through deltopectoral approach, the fracture was exposed and reduced with minimal soft tissue dissection. The greater tuberosity was reduced and fixed temporarily with $\mathrm{K}$ wires to the humeral head. In case of obvious rotation or displacement of the humeral head, a joystick technique was used Then the shaft fragment was reduced by abduction, traction and rotation of the arm. Reduction was checked under image intensifier both AP and lateral views. Definitive fixation with locking plate was done with plate positioned lateral to bicipital groove sparing tendon of long head of biceps and $1 \mathrm{~cm}$ distal to greater trochanter. The screws were chosen according to 
preoperative planning, and all the four head screws were inserted to the humoral head fragment. The inferior screws supporting the humeral head were considered critical. Proximal locking screws were inserted to hold the humeral head. All proximal locking screws were placed in a unicortical fashion through an external guide and confirmed to be within the humeral head with intraoperative fluoroscopy. AP (internal and external rotation) views and axillary views 90 degrees to each other were used to visualize screw placement. The distal shaft screws were placed bicortically. A minimum of three bicortical screws were used. Fluoroscopic images were taken to confirm satisfactory fracture reduction, plate positioning and proper length of screws in the humeral head. In case of severe comminution or instability, the rotator cuff, the greater tuberosity, and the lesser tuberosity were fastened to the plate using nonabsorbable sutures. Range of motion of shoulder was checked on the table for impingement. Wound was closed under negative suction, which was removed after 48 hour.

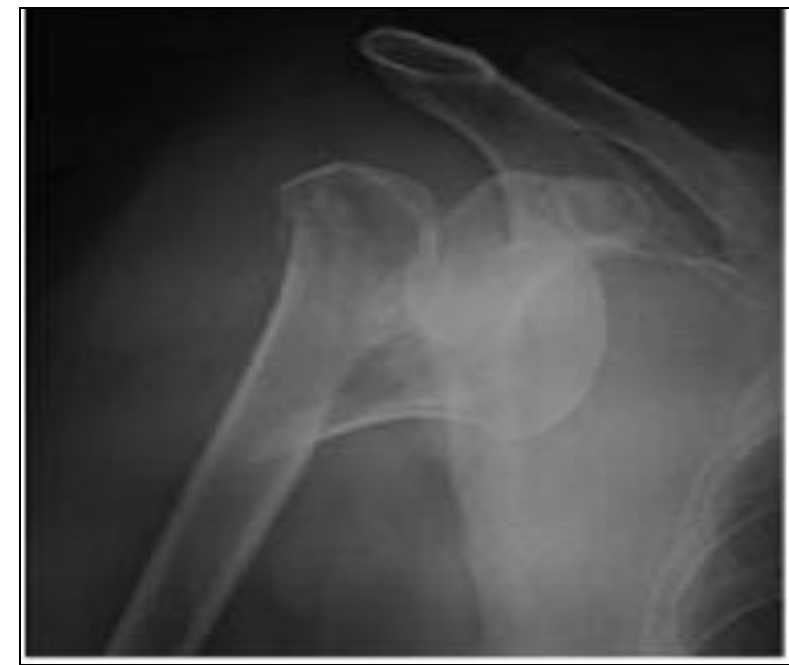

Fig 1: (a) Pre op radiograph

\section{Group-B}

\section{Percutaneous k-wire fixation}

Patient was put on the beach chair position. Near anatomical reduction was achieved by manual traction and arm mobilization. Three to four threaded $2.5 \mathrm{~mm} \mathrm{~K}$-wires under image intensifier were inserted depending on the number of fracture fragments. In the case of difficult reduction one $\mathrm{K}$ wire of $3.5 \mathrm{~mm}$ (Figure 2a, 2b) was used as a joystick.

Care was taken on the orientation and pin placement to avoid injury to the axillary nerve, the radial nerve and the anterior circumflex humeral vessels lying medially. K-wires were left out of skin and bent at the extremity to control migration. Patients were encouraged to start active mobilization of wrist

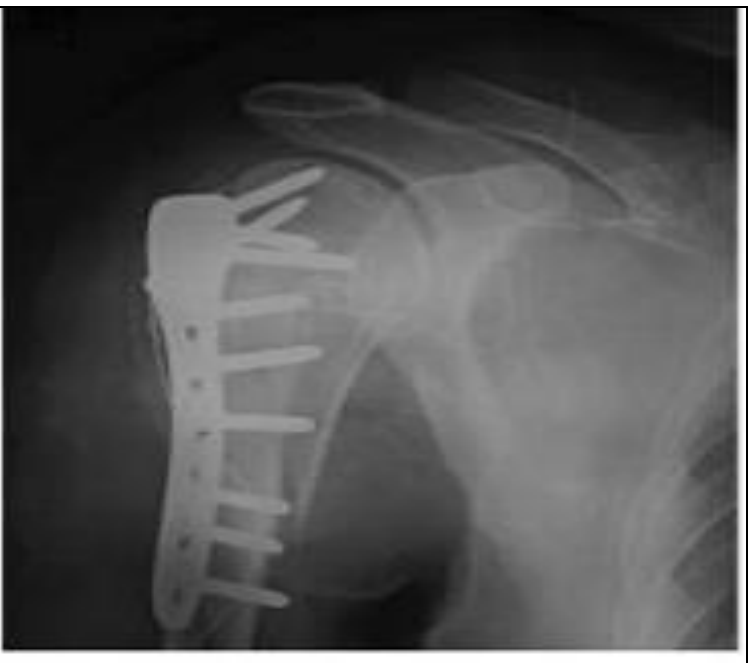

Fig 2: (b) Post op radiograph

and elbow on the second postoperative day. Dressing of the pin tracts were done on alternate days. Passive ROM exercises were initiated on the second postoperative day. Active shoulder mobilization exercises were started at 4 to 6 weeks postoperatively depending on patient's co-operation. Follow up protocol was undertaken at one week, then every month for 6 week and then at 3 months and 6 months for final evaluation. Standard anteroposterior, axillary and lateral radiographs were obtained and evaluated for bony healing, non-union, malunion, loosening of implant, loss of reduction and avascular necrosis of head of humerus. The criteria for radiographic healing was when all fragments showed substantial cortical continuity.

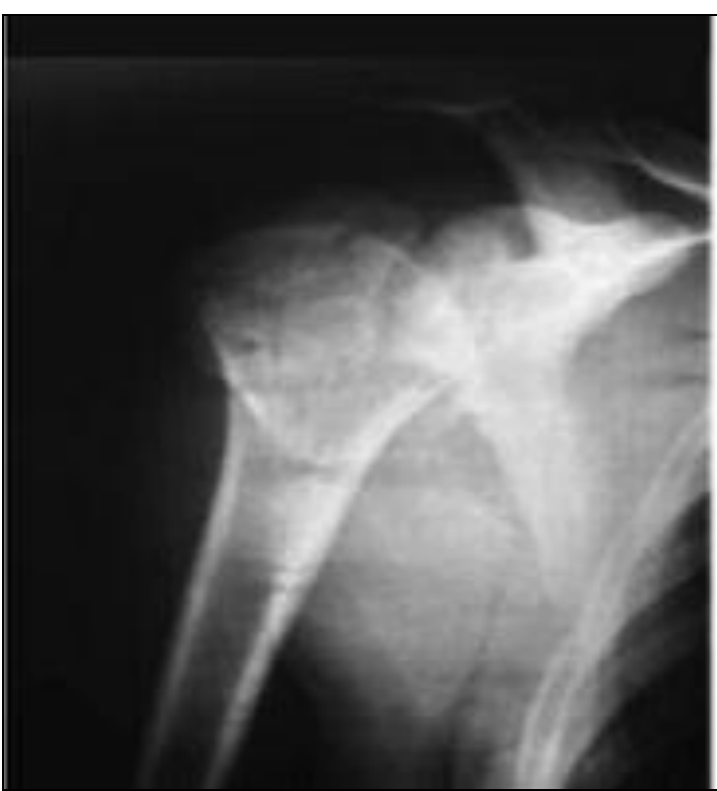

Fig 3: Pre operative radiograph

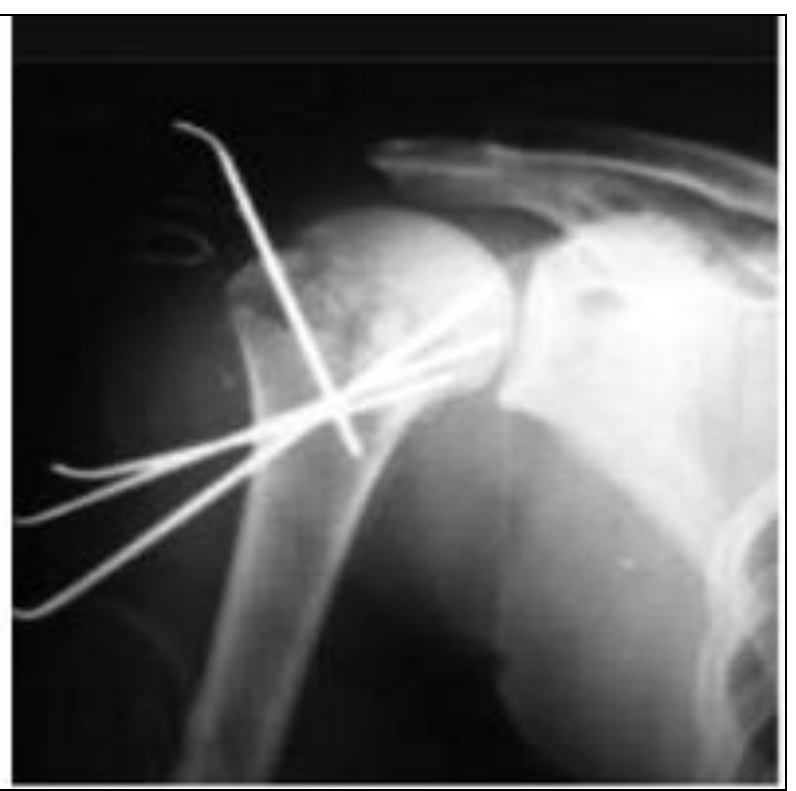

Fig 4: Post Operative radiograph 
Functional results ${ }^{[8]}$

The final result were evaluated using Neer"s score. This system is based on 100 units. Pain is the most important consideration to the patient and is assigned 35 units. The result in any patient with significant pain is graded as failure.

\section{Postoperative management}

- All patients were immobilized in shoulder immobilizer

- Appropriate antibiotics and analgesics were used.

- Immediate post-operative radiographs were taken to determine the bone alignment and maintenance of reduction.

- $\quad$ Sutures removed by 14 th day in PHILOS group.

- $\quad$ Pin tract dressing done alternate day in k-wire group.

Rehabilitation: ${ }^{[1,4,46]}$

- Pendulum exercises was started immediately depending on pain.
- $\quad$ Passive range of motion started at 1 st week

- The active range of motion was started at 2-4 weeks postoperatively, depending on stability of osteosynthesis and bone quality.

- $4^{\text {th }}$ to $6^{\text {th }}$ week-immobilization discontinued

- Active assisted movements started up to 90 abduction with no forced external Rotation.

- $6^{\text {th }}$ to $8^{\text {th }}$ week-full range of movements with active exercises started.

The patients were examined clinically and radiologically. They were assessed for range of motion and bony union and complication. Further follow-ups were done at 6 weeks, 12 weeks, and 24 weeks. The patient with shoulder stiffness given physiotherapy for 1 week to 15 days on outpatient basis.

\begin{tabular}{|c|c|c|c|}
\hline 1. Pain (35 units & & $\begin{array}{l}\text { 4. Range of motion (25 units) } \\
\text { Flexion (sagittal plane) }\end{array}$ & \\
\hline a. None/ignores & 35 & 180 & 6 \\
\hline $\begin{array}{l}\text { b. Slight, occasional, no compromise in } \\
\text { activity }\end{array}$ & 30 & 170 & 5 \\
\hline c. Mid, no effect on ordinary activity & 25 & 130 & 4 \\
\hline $\begin{array}{l}\text { d Moderate, tolerable, makes concessions, } \\
\text { uses aspirin }\end{array}$ & 15 & 100 & 2 \\
\hline e. Marked, serious limitations & 5 & 80 & 1 \\
\hline f Totally disabled & 0 & Less & 0 \\
\hline 2 Function (30 units) & & Extension & \\
\hline a. Strength & & 45 & 3 \\
\hline Normal & 10 & 30 & 2 \\
\hline Good & 8 & 15 & 1 \\
\hline Fair & 6 & Less & 0 \\
\hline Poor & 4 & Abduction (coronal plane) & \\
\hline Trace & 2 & 180 & 6 \\
\hline Zero & 0 & 170 & 5 \\
\hline h. Reaching & & 140 & 4 \\
\hline Top of head & 2 & 100 & 2 \\
\hline Mouth & 2 & 80 & 1 \\
\hline Belt buckle & 2 & Less & 0 \\
\hline Opposite axilla & 2 & External rotation (from & \\
\hline Brassiere hook & 2 & $\begin{array}{l}\text { anatomical position with elbow } \\
\text { bent }\end{array}$ & \\
\hline c. Stability & & 60 & 5 \\
\hline Lifting & 2 & 30 & 3 \\
\hline Throwing & 2 & 10 & 1 \\
\hline Pounding & 2 & Less & 0 \\
\hline
\end{tabular}




\begin{tabular}{|l|l|l|l|}
\hline Pushing & 2 & & \\
\hline Hold overhead & 2 & $\begin{array}{l}\text { Intemal rotation (from anatomical } \\
\text { positionwith elbow bent }\end{array}$ & \\
\hline $\begin{array}{l}\text { 3. Anatomy (10 units) rotation, angulation, } \\
\text { joint incongruity, retracted tuberosities, } \\
\text { failure metal, myositis, non-union, avascular } \\
\text { necrosis) }\end{array}$ & $\begin{array}{l}90(\mathrm{~T}-6) \\
70(\mathrm{~T}-12) \\
50 \text { (L-5) } \\
30 \text { (gluteal) } \\
\end{array}$ & $\begin{array}{l}\text { Less } \\
10\end{array}$ & 3 \\
\hline None & 8 & & 3 \\
\hline Mild & 4 & & 0 \\
\hline Moderate & $0-2$ & & \\
\hline Marked & & \\
\hline
\end{tabular}

\section{Neer's scoring criteria}

Neer's criteria (reference from-journal of orthopedic trauma) Criteria for evaluation of results

\section{Total points}

- Excellent Results Above 89 units

- $\quad$ Satisfactory between 80 units to 89 units

- Unsatisfactory 70 Units to 79 units

- $\quad$ Failure Below 70 Units

\section{Statistical Methods}

Categorical variables are expressed as Number of patients and percentage of patients and compared across the 2 groups using Pearson's Chi Square test for Independence of Attributes.

Continuous variables are expressed as Mean \pm Standard Deviation and compared across the 2 groups using unpaired $t$ test. The statistical software SPSS version 20 has been used for the analysis. An alpha level of $5 \%$ has been taken, i.e. if any $\mathrm{p}$ value is less than 0.05 it has been considered as significant.

Ethical Consideration: The ethical board of Narayan Medical College \& Hospital, Jamuhar Sasaram has approved the study.

\section{Results}

In our series of study, majority of the patients were males, elderly aged, with h/o fall and few with RTA. Being the commonest mode of injury, involving 2 part, 3part and 4part fractures of proximal humerus. The fractures united in all 30 patients. Excellent (60\%) satisfactory (33.33\%) and unsatisfactory (6.67\%) with PHILOS plate (Group A) and kwire (Group B) Excellent (13.33\%) satisfactory (46.67\%) unsatisfactory $(33.33 \%)$ failure $(6.67 \%)$ results were found as per Neer's criteria.

There were $100 \%$ union rates in both grous but 86.67 score in Group A(philos) and 80.8 score in Group B (percutaneous kwire) achieved according to Neer's scoring criteria for functional outcome.

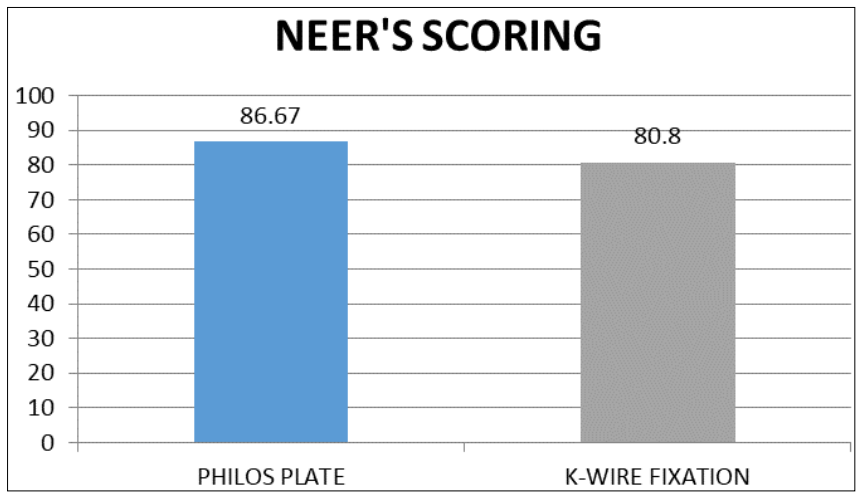

Diagram 5: 12(B) Neer's Scoring

\section{Postoperative Complications}

In PHILOS group one case had paresthesia along the line of incision. There was over distraction at fracture site in one patient, which was reduced, in subsequent follow up. None had surgical site infection. In k-wire group, one patient developed pin tract infection, two patient with pin loosening which was treated with irrigation followed by antibiotic therapy, the wound healed uneventfully. None had serious complication.

All fracture in both groups united with good functional ability by 3 months. On an average of 10 weeks ( 8 to 12 weeks). There were no case of failure in union in our study. In comparison to other study on surgical management of proximal humerus we had similar results.

Table 4: Final Radiological and Functional Evaluation.

\begin{tabular}{|c|c|c|c|c|}
\hline S no. & Parameters & Normal Values & Group A & Group B \\
\hline 1 & Flexion & $0-180$ & $156.80 \pm 19.639$ & $149.80 \pm 17.39$ \\
\hline 2. & Abduction & $0-180$ & $148.80 \pm 24.96$ & $130.80 \pm 12.42$ \\
\hline 3. & External Rotation & $0-90$ & $69.80 \pm 16.56$ & $62.55 \pm 16.23$ \\
\hline 4. & Internal Rotation & $0-90$ & $70.50 \pm 15.33$ & $60.30 \pm 11.47$ \\
\hline
\end{tabular}

\section{Discussion}

Proximal humerus fracture is the most common fracture of the shoulder. It is the second most common site of fracture in the upper limb after distal radius. These fractures have been treated with a wide range of options, namely non operative, ORIF, percutaneous screw/pin fixation and external fixation. Fractures of this region are common both with high-energy injuries in people of all ages, as well as with simple falls in 
older people with osteoporosis. In elderly patients fragility of the bone complicates the pattern of fracture. These patients also have comorbidities which makes the treatment of these patients even more challenging. Zyto and colleagues reported mean constant score of 65 points and no complications with conservative treatment compared with surgical approach, resulting in mean value of 60 points and with complications (avascular necrosis, infection) ${ }^{[8]}$ Magovern, Kenner, and Nho found good constant scores with surgery and relatively few complications, with better functional scores for percutaneous fixation ${ }^{[8,9,10]}$.

Percutaneuos fixation has its limitations of poor reduction of fracture fragments, pin tract infection and long period of recovery ${ }^{[8,10]}$.

But it has the advantages of less soft tissue stripping with less exposure, less blood loss and minimal invasiveness.

In cases where there is loss of reduction due to pin loosening, ORIF can be performed ${ }^{[10]}$ ORIF with PHILOS plate for treatment of proximal humerus fractures has the advantages of accurate reduction, early fractures has the advantages of accurate reduction, early mobilization, better fixation in osteoporotic bones and ease of reconstruction of comminuted irreducible fractures. On the other hand it has the disadvantages of excessive soft tissue dissection and blood loss, risks of injury to the neurovascular structures and increased risk of avascular necrosis of humeral head [11, 12] However, recent studies have shown good long term results of proximal humerus fractures managed by the PHILOS plate ${ }^{[13,}$ 14]

In a study conducted by Fazal et al. it was seen that PHILOS plate fixation provided stable fixation with minimal implant problems and enabled early range of motion exercises to achieve acceptable functional results ${ }^{[15]}$.

In the present study it was concluded that PHILOS plate provides an excellent stable construct even in multi fragmented osteoporotic proximal humerus fractures with the advantag es of accurate reduction and early mobilization. Fixation with percutaneous K-wires may present an efficient treatment option for 2 or 3 part proximal humerus fractures with its advantages of minimal invasiveness and less soft tissue dissection. Better functional results were seen in patients treated with PHILOS plate than those treated with percutaneous K-wire fixation.

Table 3: Comparison in mode of injury

\begin{tabular}{|c|c|c|}
\hline Mode Of Injury & Rta & Fall \\
\hline MA Fazal $^{32}$ & 6 & 21 \\
\hline Herbert Resch $^{43}$ & 24 & 3 \\
\hline Present Study & 12 & 18 \\
\hline
\end{tabular}

\section{Fracture classification}

Proximal humerus fractures were classified according to Neer"s classification using X-rays. Most common fracture part in the study population was

- Two part fractures $(\mathrm{n}=11) 56.7 \%$

- Three part fractures $(n=17) 33.3 \%$

- Four part fractures $(\mathrm{n}=3) 10 \%$ respectively.

\section{Outcome variables}

\section{Duration of surgery}

The mean time of surgery for PHILOS group was $102 \pm 9.22$ min and for k- wire group was $60.67 \pm 23.06$ minutes. The difference between the two groups was found to be statistically significant ( $\mathrm{p}$-value $<0.0001$.) as open reduction and philos plate fixation is more technically demanding procedure. The surgeon needs to be more meticulous in dissection of tissues, fracture reduction, application of plate and wound closure, it needs more time than percutaneous kwire fixation in proximal humerus fracture.

\section{Amount of Blood loss during surgery}

Mean blood loss in the PHILOS group was $710 \pm 105.56 \mathrm{ml}$ and in the k-wire group was $127 \pm 182.3 \mathrm{ml}$. The Difference between the two groups was statistically significant $(<0.0001)$. The difference in blood loss was attributed mainly because application of philos plate as it was largely a open procedure with significant soft tissue dissection thus blood loss while the application of $\mathrm{k}$-wire was percutaneous procedure under c-arm controlled so less blood.

\section{Pain (VAS)}

Pain was measured in both the groups using 10-point Visual Analogue Scale (VAS) at $3^{\text {rd }}$ day, 1 week, 2 week and at final follow-up at 24 weeks (delayed). The mean score for pain was comparable in both the groups with only poorer mean score at $3^{\text {rd }}$ day for plating group again possibly due to significant tissue dissection.

\section{Functional Ability (Quick DASH score)}

The two groups were comparable in terms of subjective evaluation of the upper limb function. The mean Quick DASH score was slightly better at 18 weeks \& 20 weeks for philos group with mean value of 16.93 and 14.73 however the score at 24 weeks for both the groups was identical (13.27 and 13.27). The difference was not statistically significant $(\mathrm{p}=1)$.

\section{Percutaneous k-wire fixation}

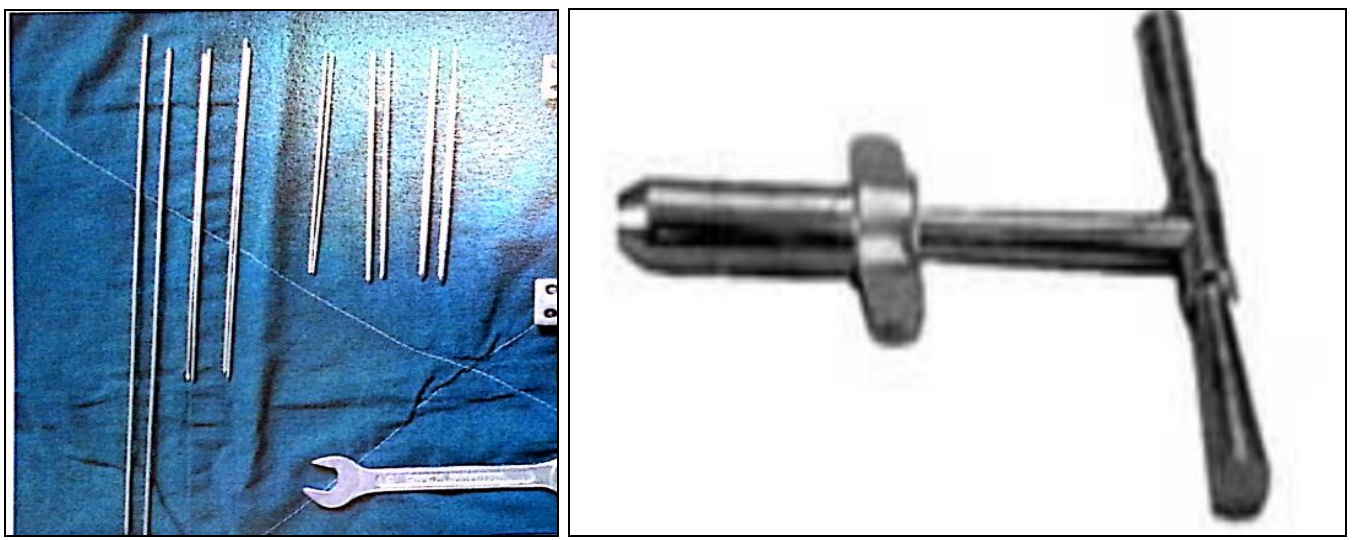

Instuments Used In K-Wire Fixation 


\section{Percutaneous K-Wire Fixation}

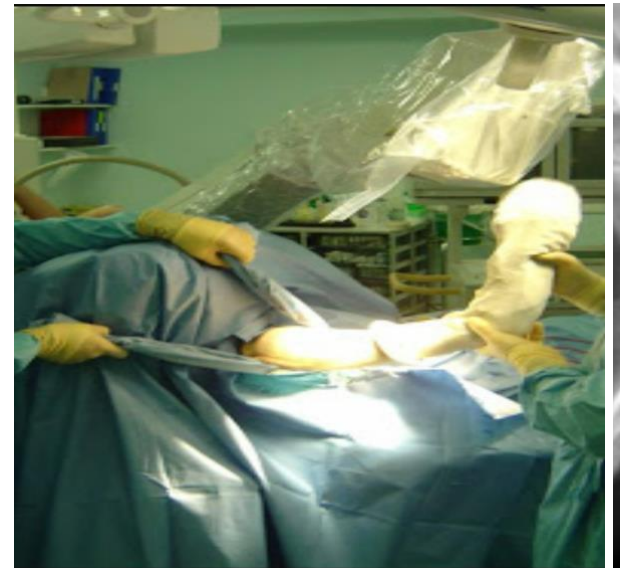

1. Patient positioning for $k$-wire fixation

Philos Plating

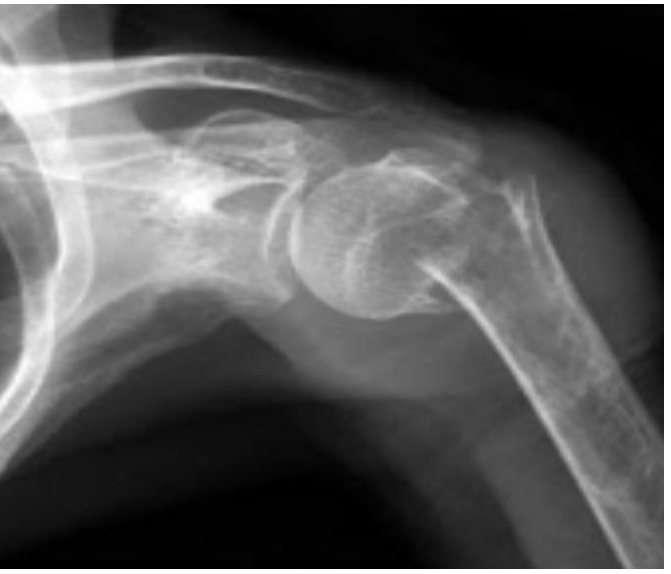

2. Pre operative xray taken under c-arm

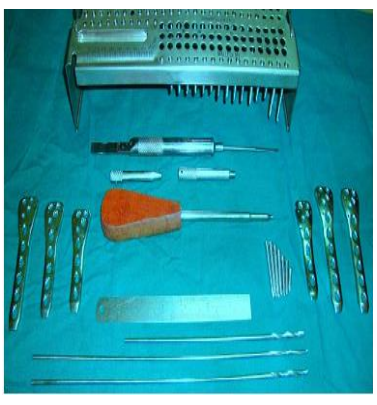

1. Instrumentation

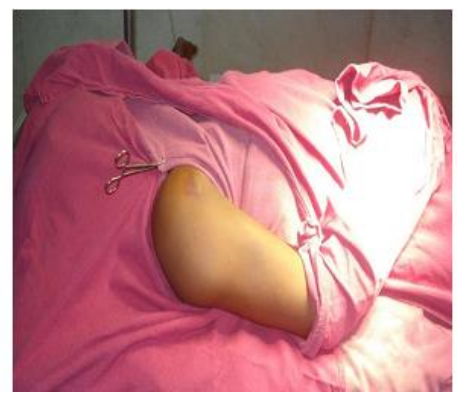

2. Patient Positioning

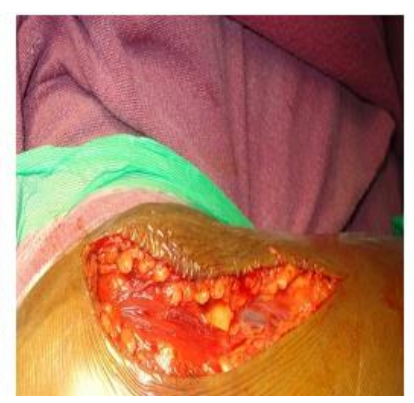

3. Incision given

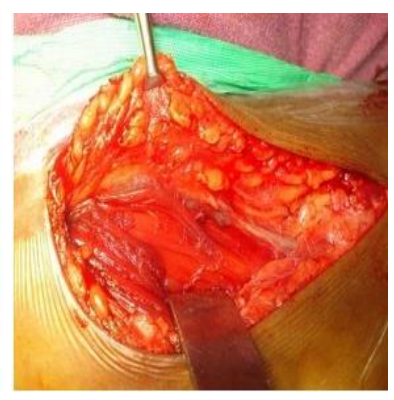

4. Deltopectoral groove exposed

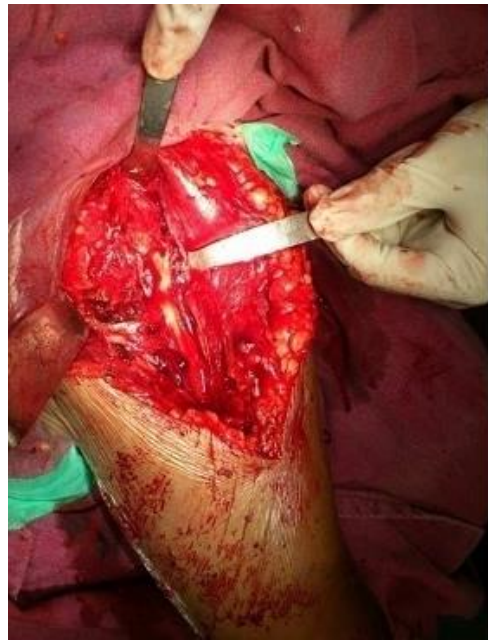

5. Fracture exposed

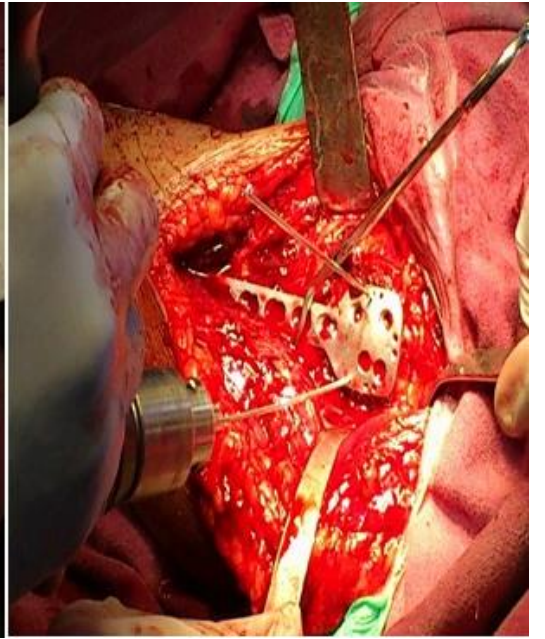

6. Reduced and fixed with kwire

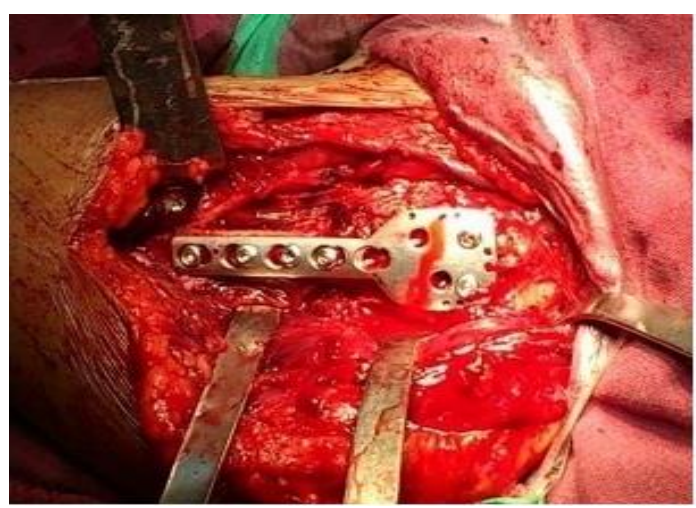

7. Reduced fracture with philos

Cases and follow up

Case 9: Percutaneou K- Wire Fixation $\sim 404 \sim$ 


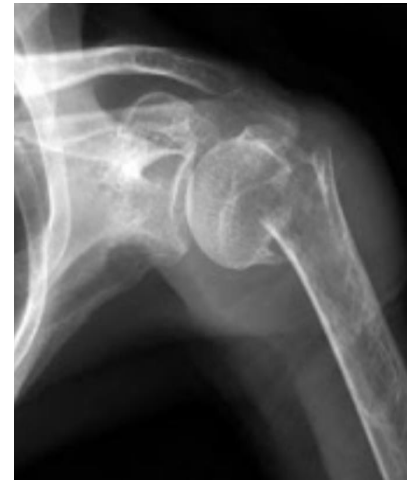

Post trauma xray

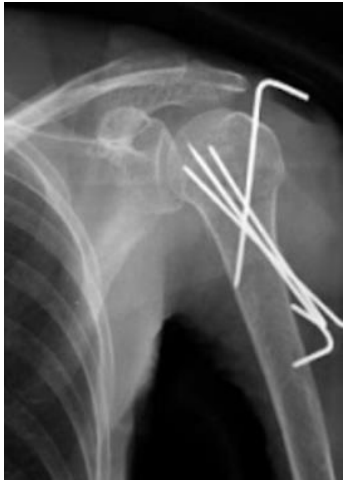

Intra operative xray

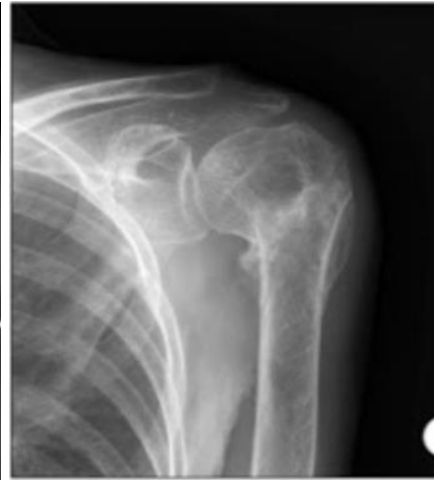

Six months post operative-xray

Clinical photographs: range of movements
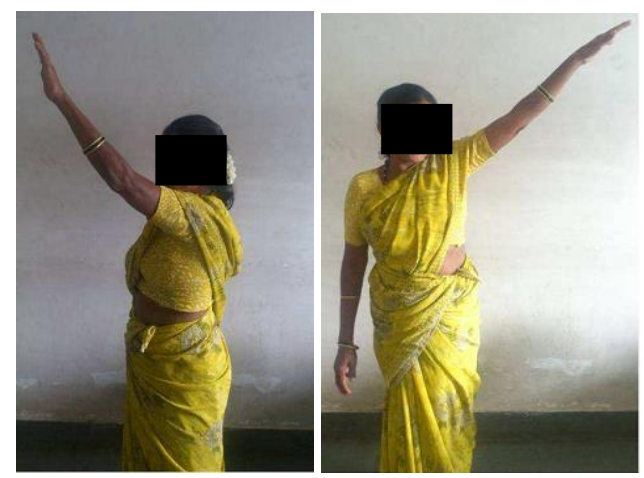

CASE. 15: ORIF with PHILOS

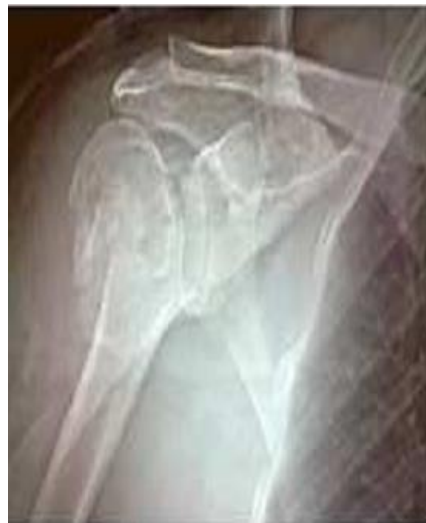

X-ray-AP View

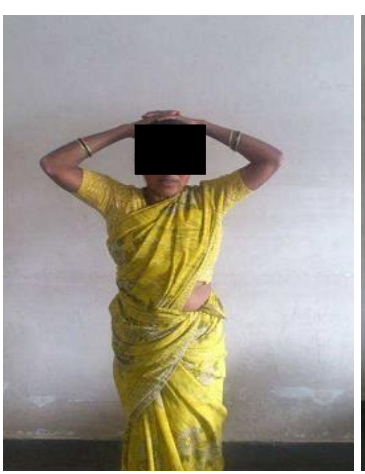

5. ORIF with PHILOS

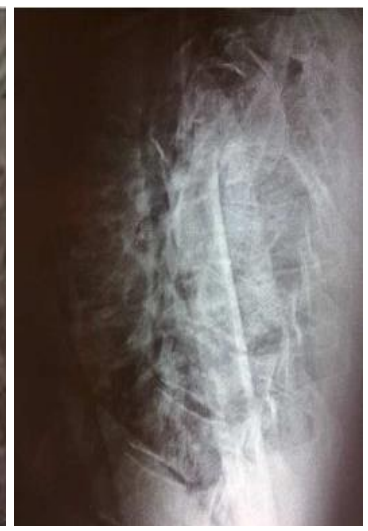

Scapular Y-View

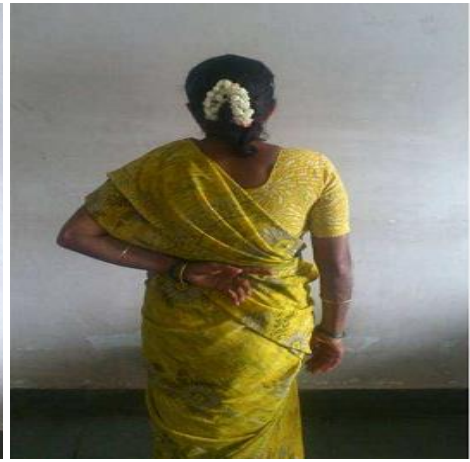

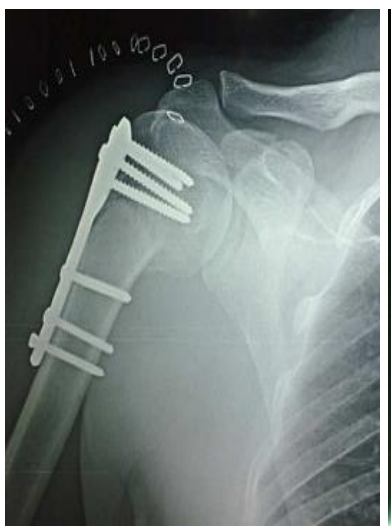

Post op x-ray

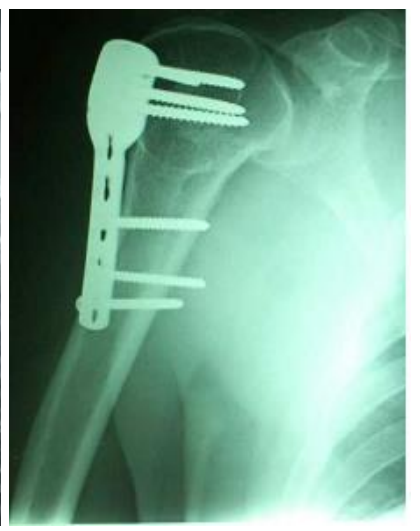

Six month post op x-ray

\section{Clinical Photographs}

Range of Movements
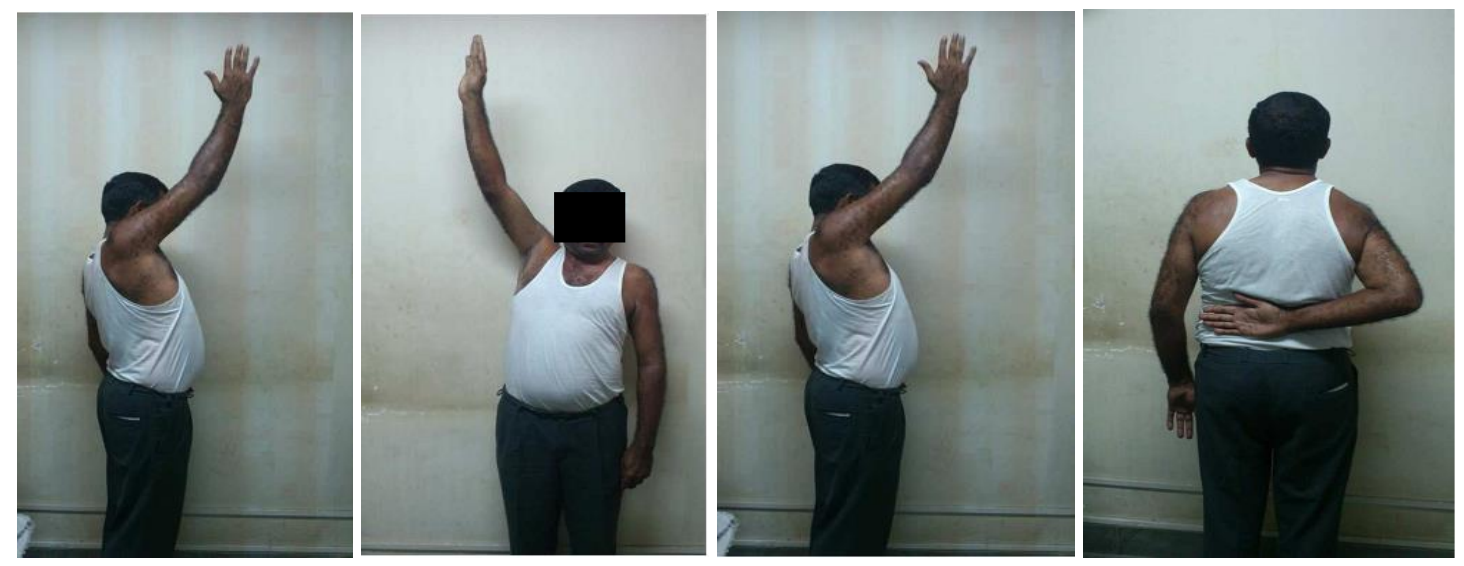


\section{Conclusion}

The present study showed that

- In elderly population, comminuted proximal humerus fracture can be successfully treated with percutaneous kwire fixation as well as open reduction and internal fixation with Philos with equal success.

- Although the radiological results are slightly better with the PHILOS than percutaneous k-wire fixation, there is no difference in functional outcome.

- In elderly population, both the modalities of treatments give comparable result, k-wire fixation is preferred as it requires less intra-operative time, less blood loss, less trauma to soft tissues, less cost but but it requires $\mathrm{C}$-arm control.

- As other medical comorbidities accompany the elderly patients and are fitness for anesthesia fitness is sometimes in question, $\mathrm{K}$-wire fixation is preferred.

- Both the modalities of treatments are associated with complications, which is more severe in k-wire fixation group then PHILOS group due pin loosening in osteoporotic bones in the elderly.

\section{References}

1. Handoll HH, Gibson JN, Madhok R. Interventions for treating proximal humeral fractures in adults. Cochrane Database Syst Rev. 2003; 4:434.

2. Clifford PC. Fractures of the neck of humerus: A review of the late results. Injury. 1980; 12:91-5.

3. Stableforth PG. Four part fractures of the neck of humerus. J Bone Joint Surg Br. 1984; 66:104-8.

4. Zyto K, Ahrengart L, Sperbert A, Torknvist H. Treatment of displaced proximal humeral fractures in elderly patients. J Bone Joint Surg [Br]. 1997; 79:512-7.

5. Ring D. Current concepts in plate and screw fixation of osteoporotic proximal humerus fractures. Injury. 2007; 3:559-68.

6. Reitman RD, Kerzhner E. Reverse shoulder arthroplasty as treatment for comminuted proximal humeral fractures in elderly patients. Am J Orthop. 2011; 40:458-61.

7. Esen E, Dogramci Y, Gultken S, Deveci MA. Factors affecting results of patients with humeral proximal end fractures undergoing primary hemiarthroplasty: A retrospective study in 42 patients. Injury. 2009; 40:133641.

8. Magovern B, Ramsay ML. Percutaneous fixation of proximal humerus fractures. Orthop Clin North Am. 2008; 39:405-16.

9. Nho SJ, Brophy RH, Baker JU, Cornell CN, Mac Gillivray JD. Management of proximal humerus fractures based on current literature. J Bone Joint Surg [Am]. 2007; 89:44-58.

10. Kenner JD, Parsons BO, Flatow EL, Rogers K, Williams GR, Galatz LM. Outcomes after percutaneous reduction and fixation of proximal humerus fractures. J Shoulder Elbow Surg. 2007; 16:330-8.

11. Siegel J, Dines D. Proximal humerus malunions. Orthop Clin North Am. 2000; 31:35-49.

12. Wijgman AJ, Roolker W, Pall TW, Raaymakers EL, Marti RK. Open reduction and internal fixation of threeand four-part fractures of the proximal part of the humerus. J Bone Joint Surg. 1970; 52:1077-89.

13. Hirschmann MT, Falleger B, Amsler F, Regazzoni P, Gross T. Clinical longer term results after internal fixation of proximal humerus fractures with alocking compression plate (PHILOS). J Orthop Trauma. 2011;
25:286-93.

14. Olerud P, Ahrangart L, Ponzer S, Saving J, Tidermark J. Internal fixation versus non operative treatmentt of displaced 3 part proximal humerus fractures in elderly patients: A randomised controlled trial. J Shoulder Elbow Surg. 2011; 20:747-55.

15. Fazal. PHILOS plate fixation for displaced proximal humeral fractures. J Orthop Surg. 2009; 17(1):15-8.

16. Robinson CM, Christie T. Two part proximal humeral fracture: A review of operative treatment using two techniques. Injury. 1993; 24(2):123-125.

17. Zyto K, Wallace WA, Frostick SP, Preston BJ. Outcome after hemiarthroplasty for three and four part fracture of the proximal humerus. J Shoulder Elbow Surg, 1998; 7:85-9.

18. Koval KJ, Blair B, Takie R, Kummer FT, Zuckerman D. Surgical nerve fractures of proximal humerus; a laboratory evaluation of ten frixation techniques. J Trauma. 1996; 40(S):778-783.

19. Hessmann M, Gehling H, Gotzenl, Plate fixation of proximal humerus fracture with indirect reduction; surgical technique and results using the shoulder score. Injury. 1999; 30:453-462. 95

20. Hintermann B, Trouillier HH, Schufer D. Rigid internal fixation of fractures of the proximal humerus in older patients. J Bone Joint Surg (Br). 2000; 82(8):1107-1112.

21. Wijgman A.J, Roolker W, Patt TW. open reduction and internal fixation of three and four part fractures of proximal humerus. Scientific Article 01, 2002.

22. Jan-Magnus Björkenheim, Jarkko Pajarinen. Internal fixation of proximal humeral fractures with a locking compression plate. Acta Orthop Scand. 2004; 75(6):741745.

23. Gerber C, Worner CM, Vienne P. Interal fixation of complex fractures of the proximal humerus. J Bone Joint Surg (Br). 2004; 86(60):848-855.

24. Charalambous CP, Siddiqe I. Proximal humerus internal locking for the treatment of proximal humerus fracture. Archieve of orthopaedic and trauma surgery. 2007; 127:205-210.

25. Reto Babst, Flexi Brunner. Plating in proximal humeral fractures. European Journal of trauma and emergency surgery. 2007; 33:345-56.

26. Moonot P, Ashwood N, Hamlet M. Early results for treatment of three- and four-part fractures of the proximal humerus using the PHILOS plate system. J Bone Joint Surg Br. 2007; 89(9):1206-9.

27. Ramchander Siwach, Roop Singh, Rajesh Kumar Rohilla. Internal fixation of proximal humerus fracture by locking proximal humerus plate in elderly osteoporotic. J Orthopaed Traumatol. 2008; 9:149-153, 96.

28. Rizwan Shahid. proximal humerus fracture treated with locking compression plate. Acta Orthop. Belg., 2008; 74:602-608.

29. Kenneth Egol A, Crispin Ong C, Michael Walsh. Early complication of proximal humerus fractures treated with locked plates, Jorthop trauma. 2008; 22:159-164.

30. Felix Brunner, Christoph Sommer, Christian Bahrs. Open Reduction and Internal Fixation of Proximal Humerus Fractures Using a Proximal Humeral Locked Plate: A Prospective Multicenter Analysis, J Orthop Trauma. 2009; 23:163-172.

31. Martinez AA. proximal humerus locking plate for proximal humerus fracture - retrospective study. Journal of orthopaedic surgery. 2009; 17(1):10-4 
32. Fazal MA, Haddad FS. PHILOS plate fixation for displaced proximal humeral fractures. Journal of orthopaedic surgery. 2009; 17(1)15-8.

33. Sameer Aggarwal. Displaced proximal humeral fractures:an Indian experience with locking plate. Journal of Orthopaedic surgery and research. 2010; 5:60.

34. Georg Osterhoff, Christian Ossendorf. The calcar screwin angular stable plate fixation of proximal humerus fractures-a case study. Journal of orthopedic surgery and research. 2011; 6:50.

35. Adithya pawaskar c, kee-won lee. locking plate for proximal humerus fracture in the elderly population:serial change in neck shaft angle. clin orthop surg. 2012; 4(3)209-215.

36. Christopher Jobe M. Gross anatomy of the shoulder. Chapter-2, In: The Shoulder, Vol.1, edt. Charles A. Rcockwood Jr., Frederick A. Matsein II, Philadelphia: W.B. Saunders Company. 1990; 97:34-97.

37. Rothmann TB, Mainab I. The microvascular pattern of rotator cuff. J Bone Joint Surg. 1970; 52B:540-553.

38. Gerber $C$. The arterial vascularization of the humeral head. J Bone Joint Surg. 1990; 72A:1486-1493.

39. Lind T, Kronerk Jensen J. The epidemiology of fractures of proximal humerus. Arch Orthop Trauma Surg. 1989; 108:285.

40. Scott Powell E, Robert Chandler W. Fractures of the proximal humerus. Chapter-11, In: Text book of Operative techniques in upper extremity sports injuries. Ed.Frank W. Jobe, Mosby, 1995, 313-340.

41. Evan Flatow L. Fracture of the proxiaml humerus. Chapter-25, In: Text book of Rockwood and Green's fractures in adults. New York: Lippincott Willimas \& Wilkins. 2001; 1:997-1035.

42. Zuckerman JD. Axillary artery injury as complication of proximal humerus fractures. Clin Orthop 1984; 189: 234.

43. Strohm PC, Helwig GP. Locking Plates in Proximal Humerus Fractures. ACTA. 2007; 74:410-415.

44. Georg Osterhoff, Christian Ossendorf. The calcar screw in angular stable plate fixation of proximal humeral fractures - a case study. Journal of Orthopaedic Surgery and Research. 2011; 6:50.

45. Stanley Hoppenfield. Operative exposure 4th edition, 415. 98.

46. Hong-fei Shi, Jin Xiong, Yi-xin Chen. Management of proximal humeral fractures in elderly patients with unior polyaxial locking osteosynthesis system, Arch Orthop Trauma Surg. 2011; 131:541-547.

47. Sharafeldin KN, Quinlan JF, Corrigan J. Functional follow-up of locking plate Wxation of fractures of the proximal humerus. Eur J Orthop Surg Traumatol. 2008 18:87-92.

48. Cuomo F, Flatow EL, Maday MG, Miller SR, Macllveen SJ, Bigiliani LU. Open reduction and internal fixation of two and three part displaced surgical neck fractures of proximal humerus. J Bone Joint Surg. 1992; 1:287-293.

49. Kenneth Egol A, Crispin Ong C, Michael Walsh. Early complication of proximal humerus fractures treated with locked plates, Jorthop trauma. 2008; 22:159-164.

50. Aksu N, Göğü A, Kara AN, Iiklar ZU. Complication of proximal humerus fractures treated with locked plates, Acta Orthop Traumatol Turc. 2010; 44(2):97-104.

51. Esser RD. Open reduction and internal fixation of three and four part fractures of proximal humerus". Clin Orthop. 1994; 299:244-251. 99.

52. Zyto K, Kronberg M, Brostorm LA. Shoulder function after displaced fractures of the proximal humerus. J Bone Joint Surg. 1995; 4:331-336.

53. Leonard M, Mokotedi L, Alao U. The use of locking plates in proximal humeral fractures: Comparison of outcome by patient age and fracture pattern, Int $\mathrm{J}$ shoulder surgery. 2009; 3(4)85-9.

54. Lin J, Hou SM, Hing YS. Locked nailing for displaced surgical neck fractures of the humerus. J Trauama. 1998; 45(6):1051-1057.

55. Nisan Nisan, Tahir OGUT. Fixation of proximal humeral fractures with modified tension band technique. $\mathrm{J}$ of Arthoplasty and Arthoscopic Surgery. 2002; 13(3).

56. Hodgson SA, Mawson ST, Stanley JD. Rehabilitation after two part fractures of the neck of the humerus. J Bone Joint Surg (Br). 2003; 85(30):419-22.

57. Andrew H, Crenshaw Jr. Surgical techniques and approaches. Chapter-1, In: Campbell's operative orthopaedics, 10th Edn., edt. S. Terry Canale, Kay Daugherty, Linda Jones, London: Mosby Year Book Publication. 2003: 1(100):3-122.

58. Kenner JD, Parsons BO, Flatow EL, Rogers K, Williams GR, Galatz LM. Outcomes after percutaneous reduction and fixation of proximal humerus fractures. J Shoulder Elbow Surg. 2007; 16:330-8. 